\title{
Oral progesterone treatment in chronic obstructive lung disease: failure of voluntary hyperventilation to predict response
}

\author{
DOUGLASS A MORRISON, ALLAN L GOLDMAN \\ From the Department of Internal Medicine, James A Haley Veterans Hospital, Tampa, and the University of \\ South Florida College of Medicine, Tampa, Florida, USA
}

ABSTRACT Previous studies have shown that some patients with chronic obstructive lung disease and hypercapnia will respond to medroxyprogesterone with improvement in arterial blood gases. The exact mechanism of this effect is unclear but it is presumed to be a result of ventilatory stimulation. To determine whether the ability to correct arterial blood gas abnormalities by voluntary hyperventilation would predict a subsequent favourable response to progesterone, we studied 11 subjects with chronic obstructive lung disease and chronic hypercapnia. Five subjects had chronic obstructive lung disease of moderate severity with mean (SE) FEV $1.8(0.34) 1$ maximum voluntary ventilation (MVV) $40.4(7 \cdot 16) \mathrm{l} / \mathrm{min}^{-1}$, arterial oxygen tension $\left(\mathrm{PaO}_{2}\right) 53.8(2.40 \mathrm{~mm} \mathrm{Hg}$, and arterial carbon dioxide tension $\mathrm{PaCO}_{2}$ ) 49.6 (3.91) $\mathrm{mm} \mathrm{Hg}$, and were able to normalise their blood gas tensions during voluntary hyperventilation $\left(\mathrm{PaO}_{2} 85.4(8.01) \mathrm{mm} \mathrm{Hg}\right.$; $\mathrm{PaCO}_{2} 32.8(3.43) \mathrm{mm}$ $\mathrm{Hg}$ ). Six subjects had severe chronic obstructive lung disease with $\mathrm{FEV}_{1} 0.77(0 \cdot 12) 1, \mathrm{MVV} 19$ (3.09) $1 / \mathrm{min}^{-1}, \mathrm{PaO}_{2} 60.0(2.89) \mathrm{mm} \mathrm{Hg}$ and $\mathrm{PaCO}_{2} 50.5(1.38) \mathrm{mm} \mathrm{Hg}$, and they could not significantly alter their blood gases with voluntary hyperventilation $\left(\mathrm{PaO}_{2} 62.5(3 \cdot 19) \mathrm{mm} \mathrm{Hg}, \mathrm{PaCO}_{2} 49 \cdot 7(1 \cdot 84)\right.$ $\mathrm{mm} \mathrm{Hg}$ ). The groups were similar in age, height, weight, and resting $\mathrm{PaO}_{2}$ and $\mathrm{PaCO}_{2}$. Each subject received one month of oral placebo and one month of medroxyprogesterone acetate (Provera), 20 $\mathrm{mg}$ orally thrice daily, given in a randomised, double blind fashion. The groups responded similarly with a significantly higher $\mathrm{PaO}_{2}$ and lower $\mathrm{PaCO}_{2}$ while having medroxyprogesterone acetate than while having placebo. Two patients with polycythaemia showed a reduction in haemoglobin concentration while taking progesterone. It is concluded that the response to medroxyprogesterone is not predictable from spirometric or blood gas changes after voluntary hyperventilation.

Chronic hypercapnia may result from conditions that impair the function of the lungs or chest bellows, or from primary disorders of respiratory control even when mechanical lung function is normal ${ }^{1-3}$ Parenteral and oral progesterone treatment have been found to be effective respiratory stimulants in conditions characterised by abnormal respiratory control, such as the obesity-hypoventilation syndrome, ${ }^{45}$ as well as in some patients with chronic obstructive lung disease. ${ }^{6-10}$ The ability to correct raised carbon diox-

Address for reprint requests: Dr Douglass A Morrison, Cardiac Catheterisation Laboratory, Denver, Veterans Administration Medical Center, 1055 Clermont Street, Denver, Colorado 80220, USA.

Accepted 10 February 1986 ide tension $\left(\mathrm{PaCO}_{2}\right)$ with voluntary hyperventilation has been used in diagnosing the obesityhypoventilation syndrome and for predicting a successful outcome with progesterone treatment. 24511 One study suggested that response to chronic progesterone treatment among patients with chronic obstructive lung disease could be predicted from voluntary hyperventilation. ${ }^{8}$ The object of the present study was to compare the effects of medroxyprogesterone on arterial blood gas tensions in patients with chronic obstructive lung disease who could and could not reduce their $\mathrm{PaCO}_{2}$ by voluntary hyperventilation.

\section{Methods}

Twenty subjects with chronic airflow obstruction and 
Table 1 Clinical and functional characteristics of the patients (means with standard errors in parentheses)

\begin{tabular}{|c|c|c|c|}
\hline & Correctors & Non-correctors & (p) significance \\
\hline $\begin{array}{l}\text { Age (y) } \\
\text { Height }(\mathrm{cm}) \\
\text { Weight }(\mathrm{kg}) \\
\text { FEV }_{1}(\mathrm{l}) \\
\text { Maximal voluntary }^{\text {a }}\end{array}$ & $\begin{array}{c}57 \cdot 2(3 \cdot 18) \\
170(0 \cdot 94) \\
94 \cdot 0(12 \cdot 8) \\
1 \cdot 81(0 \cdot 340)\end{array}$ & $\begin{array}{l}61 \cdot 0(2 \cdot 07) \\
175(3 \cdot 74) \\
81 \cdot 0(7 \cdot 6) \\
0.77(0 \cdot 116)\end{array}$ & $\begin{array}{l}>0.2 \\
>0.3 \\
>0.3 \\
<0.01\end{array}$ \\
\hline ventilation $\left(1 \mathrm{~min}^{-1}\right)$ & $40 \cdot 4(7 \cdot 16)$ & $19.0(3.04)$ & $<0.01$ \\
\hline
\end{tabular}

chronic hypercapnia were selected from the outpatient pulmonary clinic of the James A Haley Veterans Administration Hospital. All gave fully informed consent to participate in the study. The protocol had the approval of the University of South Florida College of Medicine's Committee of Associates on Human Experimentation and the Research Committee of the Veterans Administration Medical Center.

Chronic airflow obstruction was defined as a forced expiratory volume in one second $\left(\mathrm{FEV}_{1}\right)$ of less than $80 \%$ of the predicted value, a total lung capacity (TLC) of over $80 \%$ of the predicted, and an FEV $/$ FVC ratio of less than $70 \% .^{1213}$ Chronic hypercapnia was defined as a $\mathrm{PaCO}_{2}$ of $44 \mathrm{~mm} \mathrm{Hg}$ or more on at least two occasions without concomitant metabolic alkalosis ( $\mathrm{pH} \leqslant 7 \cdot 45)$.

Initial evaluation was based on a history; physical examination, including measurement of height and weight; posteroanterior and lateral chest radiographs; an electrocardiogram; a complete blood count; blood glucose and electrolyte concentrations; spirometric indices, including maximal voluntary ventilation (MVV), and lung volumes. After local xylocaine anaesthesia, a 20G catheter was inserted percutaneously into the radial artery and arteral blood gas tensions before and two minutes after voluntary hyperventilation were determined. For the voluntary hyperventilation the patients were asked to breathe as deeply and rapidly as they could for two minutes; exhaled gases were not collected. Subjects with diabetes mellitus or atherosclerotic disease were excluded.

During the course of the study patients continued their usual treatment. An exacerbation of their underlying lung disease resulted in exclusion from the study. After initial evaluation the patients were randomly allocated in a double blind fashion to receive either medroxyprogesterone acetate (Provera), $20 \mathrm{mg}$ orally thrice daily or a placebo tablet thrice daily (supplied by the Upjohn Company, Kalamazoo, Michigan). The treatment was given for one month, after which the groups crossed over. At the end of both the first and the second months of treatment the history, physical examination (including weight measurement), electrocardiogram, blood count, blood glucose and electrolyte determinations, spirometry, and measurement of lung volumes and blood gases were repeated.

Statistical analysis of the results was performed with paired and unpaired student's $t$ tests.

\section{Results}

Eleven subjects met all of the criteria and were able to complete the protocol as described. The other nine had intercurrent chest illnesses and were therefore excluded from the study.

With voluntary hyperventilation, five of the 11 subjects were able to reduce their $\mathrm{PaCO}_{2}$ to less than 44 $\mathrm{mm} \mathrm{Hg}$ and were designated "correctors." Six of the 11 subjects were unable to reduce their $\mathrm{PaCO}_{2}$ to less than $44 \mathrm{~mm} \mathrm{Hg}$ and were designated "noncorrectors." There were no significant differences ( $p$ $>0.2$ ) in age, height, or weight between the two groups (table 1). Non-correctors, however, had much more severe chronic airflow obstruction $(p<0.01)$ as indicated by the FEV 1 and MVV (table 1).

The resting $\mathrm{PaO}_{2}$ and $\mathrm{PaCO}_{2}$ were not significantly different in the two groups. Differences were, however, noted in the values obtained after voluntary

Table 2 Arterial carbon dioxide $\left(\mathrm{PaCO}_{2}\right)$ and oxygen $\left(\mathrm{PaO}_{2}\right)$ tensions $(\mathrm{mm} \mathrm{Hg})$ at rest and after two minutes of voluntary hyperventilation (means with standard errors in parentheses)

\begin{tabular}{llll}
\hline & Correctors & Non-correctors & $(p)$ significance \\
\hline $\mathrm{PaCO}_{2}$ & & & \\
$\quad \mathrm{Rest}$ & $49 \cdot 6(3.91)$ & $50 \cdot 5(1 \cdot 38)$ & $\mathrm{NS}$ \\
$\quad \mathrm{Hyperventilation}$ & $32 \cdot 8(3.43)$ & $49.7(1.84)$ & $<0.0025$ \\
$\mathrm{PaO}_{2}$ & $53 \cdot 8(2.40)$ & $60.0(2.89)$ & $\mathrm{NS}$ \\
$\quad$ Rest & $85.41(8.01)$ & $62.57(3.196)$ & $<0.02$ \\
Hyperventilation & & & \\
\hline
\end{tabular}

Conversion: Traditional to SI units-Blood gas tensions: $1 \mathrm{~mm} \mathrm{Hg} \approx 0.13 \mathrm{kPa}$. 
Table 3 Arterial carbon dioxide $\left(\mathrm{PaCO}_{2}\right)$ and oxygen $\left(\mathrm{PaO}_{2}\right)$ tensions $(\mathrm{mm} \mathrm{Hg})$ during treatment (means with standard errors in parentheses)

\begin{tabular}{|c|c|c|c|}
\hline & Correctors & Non-correctors & (p) significance \\
\hline $\begin{array}{l}\mathrm{PaCO}_{2} \\
\text { Placebo } \\
\text { Progesterone }\end{array}$ & $\left.\begin{array}{l}50.6(1.50) \\
46.6(0.81)\end{array}\right\} *$ & $\left.\begin{array}{l}51 \cdot 3(2 \cdot 20) \\
46 \cdot 0(3 \cdot 46)\end{array}\right\} * *$ & $\begin{array}{l}\text { NS } \\
\text { NS }\end{array}$ \\
\hline $\begin{array}{l}\mathrm{PaO}_{2} \\
\text { Placebo } \\
\text { Progesterone }\end{array}$ & $\left.\begin{array}{l}56.4(3.22) \\
61.41(2.5)\end{array}\right\} *$ & $\left.\begin{array}{l}55 \cdot 2(3 \cdot 78) \\
60 \cdot 2(4 \cdot 48)\end{array}\right\} \dagger$ & $\begin{array}{l}\text { NS } \\
\text { NS }\end{array}$ \\
\hline
\end{tabular}

*Significant at $\mathrm{p}<0.05 ;{ }^{* *}$ Significant at $\mathrm{p}<0.025 ;$ +Significant at $\mathrm{p}<0.005 ; \mathrm{NS}=\mathrm{p} \geqslant 0.05$

Conversion: Traditional to SI units-Blood gas tensions: $1 \mathrm{~mm} \mathrm{Hg} \approx 0.13 \mathrm{kPa}$.

hyperventilation (table 2). With voluntary hyperventilation correctors were able to reduce their $\mathrm{PaCO}_{2}$ from 49.6 to $32.8 \mathrm{~mm} \mathrm{Hg}$ ( $\mathrm{p}<0.025$ ), whereas noncorrectors had essentially no change in $\mathrm{PaCO}_{2}$ (from 50.5 to $49.7 \mathrm{~mm} \mathrm{Hg}$; table 2). In addition, the oxygen tension $\left(\mathrm{PaO}_{2}\right)$ increased to normal values in correctors during hyperventilation, while there was no significant change in $\mathrm{PaO}_{2}$ in the non-correctors.

In essence, correctors were characterised by a moderate degree of chronic airflow obstruction, appreciable resting hypoxia and hypercapnia, and the ability to normalise their arterial blood gas tensions during voluntary hyperventilation. The noncorrectors had more severe chronic airflow obstruction with a similar degree of resting hypoxia and hypercapnia but were unable to alter their blood gases significantly during voluntary hyperventilation.

There were no significant changes in spirometric values or lung volumes while the subjects were taking medroxyprogesterone acetate or placebo. While taking medroxyprogesterone acetate, but not placebo, both groups had a significantly lower $\mathrm{PaCO}_{2}$ and a significantly higher $\mathrm{PaO}_{2}$ (table 3 ). The response to medroxyprogesterone acetate was similar in the two groups of patients, who had almost identical mean values of $\mathrm{PaO}_{2}$ and $\mathrm{PaCO}_{2}$ while taking placebo and medroxyprogesterone acetate. The changes in $\mathrm{PaO}_{2}$ are potentially important because they occurred on the steep portion of the oxyhaemoglobin dissociation curve, so that they were associated with substantial changes in oxygen saturation.

Of further interest is the fact that two correctors who had polycthaemia (haemoglobin concentrations 19.5 and $18.8 \mathrm{~g} / \mathrm{dl}$ ) showed falls in haemoglobin concentration (to 15 and $17.3 \mathrm{~g} / \mathrm{dl}$ ) while taking medroxyprogesterone acetate but not placebo.

There were no adverse effects or complications of treatment in either group. There was also no consistent symptomatic improvement in either group during this short course of treatment.

\section{Discussion}

Progesterone is known to stimulate ventilation in nor- mal subjects, in patients with the obesityhypoventilation syndrome, ${ }^{45}$ and in some patients with chronic obstructive lung disease.$^{6-10}$ The new $\frac{\sigma}{\sigma}$ observation made in this study is the identification of $\mathrm{O}$ a group of patients with chronic obstructive lung disease whose mechanical abnormality was sufficiently severe for them to be unable to correct their arterial co blood gas tensions with voluntary hyperventilation $\stackrel{5}{\oplus}$ but who did improve them with long term $\overrightarrow{\overrightarrow{0}}$ medroxyprogesterone acetate.

This finding was unexpected and its explanation is not clear. Possibilities include (1) less carbon dioxide production with medroxyprogesterone than with voluntary hyperventilation and (2) a more efficient pattern of ventilation with medroxyprogesterone than with voluntary hyperventilation, for example, increased tidal volume rather than increased venti- $\overrightarrow{\overrightarrow{0}}$ latory rate. ${ }^{8}$

Probably some patients with chronic obstructive lung disease and chronic hypercapnia, in addition to their mechanical limitation to ventilation, have an abnormal ventilatory drive that is not treated with standard medication. If some patients with chronic obstructive lung disease "won't breath" as opposed to "can't breathe," and if they could be detected and treated more effectively with a respiratory stimulant, this might considerably improve their condition.

For many years, clinicians have taken the patient's 을 ability to improve or normalise his arterial blood gas $\rightarrow$ tensions during voluntary hyperventilation to indicate a defect of central respiratory control. In our $\widetilde{N}$ study patients who could significantly reduce their $N$ raised $\mathrm{PaCO}_{2}$ by voluntary hyperventilation had less $\mathrm{N}$ severe chronic airflow obstruction than those who $\underset{D}{ }$ could not. This is consistent with findings in previous studies. $^{28913}$ Otis has explained the inability of $\mathscr{C}$

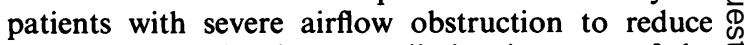
their $\mathrm{PaCO}_{2}$ during hyperventilation in terms of the associated increase in the work of breathing and carbon dioxide production that cannot be effectively $\underset{\mathbb{D}}{\stackrel{D}{D}}$ eliminated by the increased ventilation. ${ }^{14} \mathrm{~A}$ further $\frac{\mathrm{O}}{\mathrm{Q}}$ consideration is the pattern of ventilation, since $\stackrel{\mathbb{Q}}{\circ}$ increasing minute ventilation via an increased tidal volume may be more efficient than by increasing the 
respiratory rate. $^{8}$ The reason for the difference between the results in our patients and those of Skatrud et $a l^{8}{ }^{8}$ which suggested that voluntary hyperventilation did predict lack of response to medroxyprogesterone, is not clear.

A noteworthy feature of our study was the apparent reversal of polycythaemia in two patients while they were taking medroxyprogesterone acetate. This observation merits further investigation in a large group of hypoxic patients with polycythaemia. It is also possible that polycythaemia was reversed by suppression of the production of testosterone, or that retention of water while they were taking progesterone could have led to a reduced packed cell volume on a dilutional basis.

The authors would like to thank Dr Marvin Schwartz, director of the Pulmonary Disease Section, University of Colorado, and Dr John Weil, director of the Cardiovascular Pulmonary Laboratory, University of Colorado, for their thoughtful reviews of this manuscript and their constructive suggestions. The study was supported by a grant from the Upjohn Company, Kalamazoo, Michigan.

\section{References}

1 Gilbert R, Keighley J, Auchincloss JH jun. Mechanisms of chronic carbon dioxide retention in patients with obstructive pulmonary disease. Am J Med 1965; 38:217-25.

2 Rhoads GG, Brody JS. Idiopathic alveolar hypoventilation: clinical spectrum. Ann Intern Med
1969;71:271-8.

3 West JB. Causes of carbon dioxide retention in lung disease. N Engl J Med 1971;284:1232-6.

4 Lyons HA, Huang CT. Therapeutic use of progesterone in alveolar hypoventilation associated with obesity. Am J Med 1968;44:881-8.

5 Sutton FD, Zwillich CW, Creagh CE, Pierson DJ, Weil JV. Progesterone for outpatient treatment of Pickwickian syndrome. Ann Intern Med 1975;83:476-9.

6 Tyler JM. The effect of progesterone on the respiration of patients with emphysema and hypercapnia. J Clin Invest 1960;39:34-41.

7 Cullen JH, Brum VC, Reidt WU. The respiratory effects of progesterone in severe pulmonary emphysema. Am $J$ Med 1959;27:551-7.

8 Skatrud JB, Dempsey JA, Bhansal P, Irvin C. Determinants of chronic carbon dioxide retention and its correction in humans. J Clin Invest 1980;65:813-21.

9 Skatrud JB, Dempsey JA, Iber C, Berssenbugge A. Correction of $\mathrm{CO}_{2}$ retention during sleep in patients with chronic obstructive pulmonary disease. Am Rev Respir Dis 1981;124:260-8.

10 Dolly FR, Block AJ. Medroxyprogesterone acetate and COPD: effect on breathing and oxygenation in sleeping and awake patients. Chest 1983;84:394-8.

11 Rotsztain A, Haddad R, Canter HG. Blood gas changes during voluntary hyperventilation in normal and disease states. Am Rev Respir Dis 1970;102:205-12.

12 Kory RC, Callahan R, Boren HG, Syner JC. The Veterans Administration-Army cooperative study of pulmonary function: I. Clinical spirometry in normal men. Am J Med 1961;30:243-58.

13 Boren HG, Kory RC, Syner JC. The Veterans Administration-Army cooperative study of pulmonary function: II. The lung volume and its subdivisions in normal men. Am J Med 1966;41:96-114.

14 Otis AB. The work of breathing. Physiol Rev 1954; 34:449-58. 